\title{
The role of alimentary and biliopancreatic limb length in outcomes of Roux-en-Y gastric bypass
}

\author{
Sattar Darabi ${ }^{1}$, Abdoreza Pazouki ${ }^{1,2}$, Fatemeh Sadat Hosseini-Baharanchi ${ }^{3}$, Ali Kabir ${ }^{1}$, Mohammad Kermansaravi $^{1,2}$ \\ ${ }^{1}$ Minimally Invasive Surgery Research Center, Iran University of Medical Sciences, Tehran, Iran \\ ${ }^{2}$ Center of Excellence of European Branch of International Federation for Surgery of Obesity, Tehran, Iran \\ ${ }^{3}$ Department of Biostatistics, School of Public Health, Iran University of Medical Sciences, Tehran, Iran
}

Videosurgery Miniinv 2020; 15 (2): 290-297

DOI: https://doi.org/10.5114/wiitm.2019.89774

\begin{abstract}
Introduction: Roux-en-Y gastric bypass (RYGB) is one of the safe and easily reproducible bariatric procedures.

Aim: To evaluate the effect of biliopancreatic limb (BPL) and alimentary limb (AL) length on weight loss outcomes after RYGB.

Material and methods: This retrospective cohort study included 313 morbidly obese patients who underwent primary laparoscopic RYGB 2009-2015. Patients' BPL and AL lengths were categorized into three groups: group 1 (BPL: $50 \mathrm{~cm}$ and $A L: 150 \mathrm{~cm}$ ), group 2 (BPL: $150 \mathrm{~cm}$ and $A L: 50 \mathrm{~cm}$ ), and group 3 (BPL: $100 \mathrm{~cm}$ and $A L: 100 \mathrm{~cm}$ ). Data were provided from the Iranian National Obesity Surgery Database. The generalized estimating equations method was used to assess the effect of limbs length on \%excess weight loss (\%EWL).

Results: Mean \pm standard deviation age and body mass index (BMI) of 252 patients were $38.55 \pm 10.24$ years and $45.8 \pm 4.77 \mathrm{~kg} / \mathrm{m}^{2}$, respectively. Totally, $172\left(68.3 \%\right.$, BMl of $\left.46 \pm 5 \mathrm{~kg} / \mathrm{m}^{2}\right), 48\left(19 \%, B M l\right.$ of $\left.45.12 \pm 4.26 \mathrm{~kg} / \mathrm{m}^{2}\right)$, and $32\left(12.7 \%, B M I\right.$ of $\left.45.43 \pm 4.23 \mathrm{~kg} / \mathrm{m}^{2}\right)$ were in group 1,2 , and 3 , respectively $(p=0.44)$. The results showed that the choice of different limb lengths had no significant effect on \%EWL over 12 months follow-up $(p=0.625)$ adjusted for baseline BMI $(p=0.25)$. Mean \%EWL in the patients with longer BPL and shorter AL was $5.43 \%(1.91,8.95)$ higher in comparison to the patients with shorter BPL and longer AL during 36 months postoperatively adjusted for baseline $B M I(p=0.002)$.

Conclusions: During 12 months after RYGB, \%EWL was not associated with BPL or AL length. However, during 36 months postoperatively, the patients with longer BPL had a significantly higher \%EWL in comparison to the patients with shorter BPL.
\end{abstract}

Key words: weight loss, Roux-en-y gastric bypass, biliopancreatic limb, alimentary limb, generalized estimating equations.

\section{Introduction}

Morbid obesity and its related comorbidities are increasing universally [1]. Bariatric surgery is now the most effective and durable method in weight loss and resolution of obesity-related comorbidities in the morbidly obese population. Roux-en-Y gastric bypass (RYGB) is the second most common procedure among bariatric operations worldwide [2-5], with excellent results in excess weight loss (70$80 \%$ and resolution of weight-related comorbidities within the first 2 postoperative years [6].

Different findings have been obtained about the effect of biliopancreatic limb (BPL) and alimentary

Address for correspondence

Fatemeh Sadat Hosseini-Baharanchi PhD, Department of Biostatistics, School of Public Health, Iran University of Medical Sciences, Tehran, Iran, e-mail: hosseini.mstat@gmail.com, hosseini.fs@iums.ac.ir; Ali Kabir MD, PhD, Minimally Invasive Surgery Research Center, Iran University of Medical Sciences, Tehran, Iran, e-mail: aikabir@yahoo.com 
limb $(A L)$ length on the outcomes of RYGB patients [6-11], and there is not yet any consensus on the appropriate length of the BPL, AL, and common limb. Previous studies have reported contradictory results in efficacy of these limb lengths to achieve the best results in weight loss outcomes and the prevention of nutritional complications.

\section{Aim}

The aim of this study is to determine the effect of $B P L$ and $A L$ lengths on the trend of excess weight loss and body mass index (BMI) change at shortand medium-term (12 and 36 months, respectively) follow-up after RYGB. Finally, the proportion of complications is compared between various limb length groups.

\section{Material and methods}

\section{Studied sample}

This retrospective cohort study included 313 morbidly obese patients who underwent primary laparoscopic RYGB surgery, between January 2009 and March 2015. All of the procedures were performed by a single surgery team. Note that from 2013, the team had a tendency to bypass a longer BPL due to the experience of weight regain in patients. We included only patients older than 18 years old, with $\mathrm{BMI}>40 \mathrm{~kg} / \mathrm{m}^{2}$ or $\mathrm{BMI}>35 \mathrm{~kg} / \mathrm{m}^{2}$ along with at least one major comorbidity, with at least 12 months follow-up after surgery. Patients who had re-operation including conversion, reversal, and revision due to weight loss failure, and female patients who became pregnant after the surgery were excluded from the study. Data were provided from the National Obesity Surgery Database, Iran. Written informed consent was obtained from all patients before the surgery. The ethics committee of Iran University of Medical Sciences approved the study (code: IR.IUMS.REC 9502-140-27472).

\section{Variables}

The included variables were sex, age, height, preoperative weight and $\mathrm{BMI}$, comorbidities (hypertension, type 2 diabetes mellitus (T2DM), impaired glucose tolerance $(100<\mathrm{FBS} \leq 125)$, dyslipidemia, hypothyroidism, musculoskeletal pain (low-back and knee), sleep apnea, cardiovascular disease), complications, and the time of follow-up postop- eratively. The patients' weight were registered at 10 days and $1,3,6,9,12,18,24$ and 36 months after surgery.

Patients' BPL and AL lengths were measured by marked graspers with $5 \mathrm{~cm}$ by $5 \mathrm{~cm}$ measurement and categorized into three groups as follows: group 1 (BPL: $40-60 \mathrm{~cm}$ and AL: $120-150 \mathrm{~cm}$ ); group 2 (BPL: $120-150 \mathrm{~cm}$ and AL: $40-60 \mathrm{~cm}$ ); and group 3 (BPL: $95-105 \mathrm{~cm}$ and AL: $95-105 \mathrm{~cm}$ ) for convenience.

The main outcomes of the study were \%excess weight loss (\%EWL) and change in BMI ( $\triangle \mathrm{BMI})$ calculated from \%EWL = ((initial weight) - (postoperative weight) $) \times 100 /($ initial weight $)-($ ideal weight) where ideal weight is defined by the weight corresponding to a $\mathrm{BMI}$ of $25 \mathrm{~kg} / \mathrm{m}^{2}$, and $\triangle \mathrm{BMI}=$ initial BMI - postoperative $\mathrm{BMI}$, respectively [12]. Weight loss failure was defined as $\% E W L<50 \%$ at 18 months postoperatively [13]. Leak, bleeding, hypoalbuminemia (defined as at least one occurrence of albumin $<3.5 \mathrm{mg} / \mathrm{dl}$ ), and death were reported as complications. Complications were reported according to early ( $\leq 30$ days) and late (> 30 days) occurrence. Ursodeoxycholic acid $300 \mathrm{mg}$ was routinely prescribed twice daily for 6 months after the surgery. In order to look for gallstones, sonography was performed at the $6^{\text {th }}$ month and annually postoperatively.

\section{Statistical analysis}

Qualitative and quantitative variables were reported as number (\%) and mean \pm standard deviation (SD), respectively. ANOVA and independent sample $t$-test were used to compare the quantitative variables between the groups. The $\chi^{2}$ and Fisher exact tests were performed to compare the categorical variables between the groups. The generalized estimating equation method was used to assess the effect of the factors on weight loss outcome [14]. The results were reported using mean difference (95\% confidence interval) adjusted for baseline measurement and time as the concomitant variable. The data were analyzed using SPSS software v. 16.0 (IBM Corp., Armonk, NY, USA). P-values less than 0.05 were considered as significant.

\section{Results}

Twelve patients who became pregnant after the surgery were excluded from the study. Forty-nine 
patients with BPL and AL lengths out of prespecified groups were excluded from the study. Then, 252 morbidly obese patients were included in the analysis. The mean \pm SD age of the patients was 38.55 \pm 10.24 years and 209 (83\%) patients were female. The numbers (\%) of patients in groups 1,2 , and 3 were 172 (68.3\%), 48 (19\%), and 32 (12.7\%), respectively. Patients' mean \pm SD weight and BMI were $124.03 \pm 19 \mathrm{~kg}$ and $45.81 \pm 4.77 \mathrm{~kg} / \mathrm{m}^{2}$, respectively.

Table I shows that the mean \pm SD age of the patients was homogeneous between the three groups $(p=0.96)$. No significant difference was found in preoperative mean \pm SD BMI between the groups $(p=0.44$, Table I). Median (interquartile range) for follow-up time was 59.55 (50.62-68.4), 19.75 (15.86-25.81), and 14.01 (13.36-15.63) months for groups 1, 2, and 3, respectively.

Patients' reported comorbidities at first visit were homogeneous between the groups except T2DM $(p=0.012)$ and sleep apnea $(p=0.035)$, which were more common in group 1 . Follow-up rates were $90 \%$, $88 \%, 88 \%, 88 \%, 84 \%, 86 \%, 70 \%, 66 \%$, and $62 \%$ at
10 days and $1,3,6,9,12,18,24$, and 36 months after the surgery, respectively. Group 3 was excluded from the 36-month analysis.

Sensitivity analysis revealed that the characteristics including baseline weight and BMI, sex, comorbidities, and follow-up time of the patients who were excluded from and included in the study were not significantly different (results not shown).

\section{\%EWL}

Figure 1 shows that the trend of mean \%EWL of the patients with longer BPL is higher compared to the patients with shorter BPL. This difference was not statistically significant, except at 3 and 6 months after the surgery (Table II).

Table III demonstrates that there is no significant difference in \%EWL in group $1(p=0.625)$ and group $2(p=0.250)$ in comparison to group 3 over 12 months follow-up controlling for baseline BMI. Table III shows that the patients with lower $\mathrm{BMI}$ at baseline had a significantly higher \%EWL $(p<0.001)$.

Table I. Patients' reported comorbidities at first visit and other characteristics of the patients in terms of limb length groups

\begin{tabular}{|c|c|c|c|c|}
\hline Characteristics & $\begin{array}{l}\text { Group } 1^{\dagger} \\
(n=172)\end{array}$ & $\begin{array}{l}\text { Group 2 } 2^{\ddagger} \\
(n=48)\end{array}$ & $\begin{array}{l}\text { Group } 3^{\S} \\
(n=32)\end{array}$ & $P$-value \\
\hline Age, mean \pm SD [years] & $38.44 \pm 10.50$ & $38.73 \pm 9.54$ & $38.90 \pm 10.200$ & 0.96 \\
\hline Preoperative weight, mean \pm SD [kg] & $125.70 \pm 19.9$ & $119.67 \pm 16.11$ & $121.50 \pm 17.20$ & 0.11 \\
\hline Preoperative BMI, mean $\pm \mathrm{SD}\left[\mathrm{kg} / \mathrm{m}^{2}\right]$ & $46.00 \pm 5.00$ & $45.12 \pm 4.26$ & $45.43 \pm 4.23$ & 0.44 \\
\hline Sex (female), $n(\%)$ & $144(57.1)$ & $39(15.5)$ & $26(10.3)$ & 0.88 \\
\hline \multicolumn{5}{|l|}{ Preoperative BMI, $n(\%)$ : } \\
\hline$<50 \mathrm{~kg} / \mathrm{m}^{2}$ & $134(53.2)$ & $41(16.3)$ & $28(11.1)$ & 0.289 \\
\hline$\geq 50 \mathrm{~kg} / \mathrm{m}^{2}$ & $38(15.1)$ & $7(2.8)$ & $4(1.6)$ & \\
\hline \multicolumn{5}{|l|}{ Comorbidities, $n$ (\%): } \\
\hline Hypertension & $37(21.5)$ & $8(16.7)$ & $5(15.6)$ & \\
\hline T2DM & $25(16.3)$ & $1(4)$ & $8(2.4)$ & 0.012 \\
\hline $\mathrm{IGT}^{\prime \prime}$ & $41(23.8)$ & $10(20.8)$ & $6(18.8)$ & 0.776 \\
\hline Dyslipidemia & $84(80.5)$ & $20(22.5)$ & $14(15)$ & 0.633 \\
\hline Hypothyroidism & $42(39)$ & $10(11)$ & $5(7.2)$ & 0.522 \\
\hline Pain (low-back and knee) & $182(72.2)$ & $64(25.5)$ & $31(9.3)$ & 0.112 \\
\hline Sleep apnea & $18(7)$ & $10(4)$ & $8(3.2)$ & 0.035 \\
\hline Cardiovascular disease & $8(3.2)$ & $1(0.4)$ & $4(1.6)$ & 0.097 \\
\hline
\end{tabular}

${ }^{\dagger} B P L-50 \mathrm{~cm}$ and $A L-150 \mathrm{~cm},{ }^{\ddagger} B P L-150 \mathrm{~cm}$ and $A L-50 \mathrm{~cm},{ }^{\S} B P L-100 \mathrm{~cm}$ and $A L-100 \mathrm{~cm}, T 2 D M-$ type 2 diabetes mellitus, "100< FBS $\leq 125$. 
Mean \%EWL was not statistically significant between the groups 36 months postoperatively (Table II, $p=0.076$ ). Table IV shows that \%EWL mean in the patients in group 1 was $5.43 \%$ lower in comparison to the patients in group 2 over 36 months after the surgery adjusted for baseline BMI $(p=0.002)$. Mean $\%$ EWL was $8.25 \%$ higher in the patients with preoperative $\mathrm{BMI}<50 \mathrm{~kg} / \mathrm{m}^{2}$ compared to the patients with preoperative $\mathrm{BMI} \geq 50 \mathrm{~kg} / \mathrm{m}^{2}$, a significant difference $(p<0.001$, Table IV).

\section{$\triangle \mathrm{BMI}$}

All the patients' mean \pm SD $\triangle \mathrm{BMI}$ reached 15.41 \pm 4.01 at the $12^{\text {th }}$ month after the surgery and remained relatively without change afterward (results not shown). Patients' BMI change was not significantly different between groups in various follow-up times (Table II).

The different limb length groups had no significant effect on $\triangle B M I$ during 12 months postoperatively, adjusted for baseline BMI ( $p=0.42, p=0.68$, Table II). Patients with lower baseline BMI had a significantly lower change in BMI $\left(-2.65 \mathrm{~kg} / \mathrm{m}^{2}, p<0.001\right.$, Table III).

At 36 months postoperatively, the mean $\triangle \mathrm{BMI}$ of the patients was not statistically significant be-

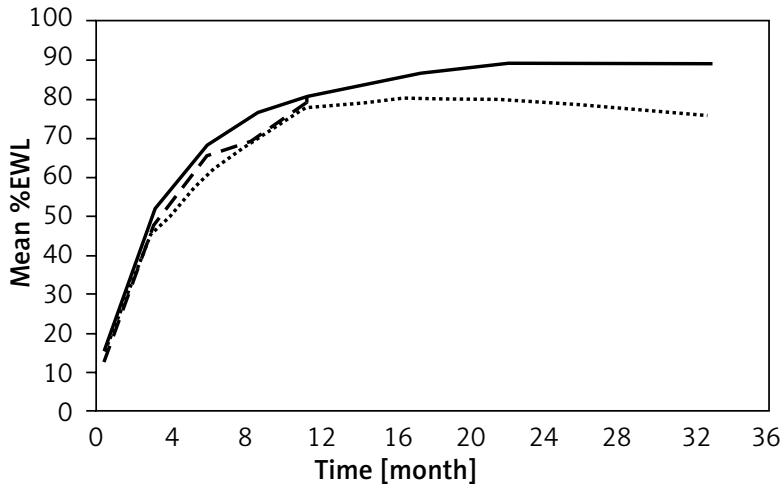

….. Group 1: BPL 50, AL $150 \longrightarrow$ Group 2 : BPL 150, AL 50 - -Group 3: BPL 100, AL 100

Figure 1. The trend of \%EWL of the patients in three groups during 36 months follow-up

tween the groups ( $p=0.167$, Table II). In addition, Table IV reveals that $\triangle \mathrm{BMI}$ was significantly lower in group 1 in comparison to group 2 controlling for baseline BMI $\left(-0.8 \mathrm{~kg} / \mathrm{m}^{2}, p=0.007\right)$. Patients who had preoperative $\mathrm{BMI}<50 \mathrm{~kg} / \mathrm{m}^{2}$ experienced a lower $\Delta \mathrm{BMI}\left(-3.07 \mathrm{~kg} / \mathrm{m}^{2}, p=0.001\right.$, Table IV).

\section{Complications}

Table $\mathrm{V}$ shows that $2(0.8 \%)$ patients died early: one patient due to sepsis because of a leak from

Table II. \%EWL and $\triangle \mathrm{BMI}$ of patients in limb length groups at different time points postoperatively

\begin{tabular}{|c|c|c|c|c|c|c|c|c|}
\hline \multirow{2}{*}{$\begin{array}{l}\text { Time } \\
\text { point }\end{array}$} & \multicolumn{4}{|c|}{$\% E W L$, mean \pm SD } & \multicolumn{4}{|c|}{$\Delta \mathrm{BMI}$, mean $\pm \mathrm{SD}$} \\
\hline & Group $1^{\dagger}$ & Group $2^{\ddagger}$ & Group $3^{\S}$ & $P$-value & Group 1 & Group 2 & Group 3 & $P$-value \\
\hline $10 \mathrm{D}$ & $\begin{array}{c}14.91 \pm 6.61 \\
(N=156)\end{array}$ & $\begin{array}{c}16.2 \pm 4.2 \\
(N=46)\end{array}$ & $\begin{array}{c}12.48 \pm 5.8 \\
(N=25)\end{array}$ & 0.052 & $3.06 \pm 1.51$ & $3.21 \pm 0.93$ & $2.5 \pm 1.11$ & 0.106 \\
\hline $1 M$ & $\begin{array}{c}24.99 \pm 9.5 \\
(N=155)\end{array}$ & $\begin{array}{c}27.38 \pm 7.34 \\
(N=45)\end{array}$ & $\begin{array}{c}23.02 \pm 9.25 \\
\quad(N=23)\end{array}$ & 0.139 & $5.02 \pm 1.73$ & $5.26 \pm 1.3$ & $4.67 \pm 1.94$ & 0.391 \\
\hline $3 M$ & $\begin{array}{c}44.02 \pm 12.73 \\
(N=157)\end{array}$ & $\begin{array}{c}50.13 \pm 11.8 \\
(N=45)\end{array}$ & $\begin{array}{c}47.7 \pm 8.62 \\
(N=20)\end{array}$ & 0.01 & $8.98 \pm 2.6$ & $9.61 \pm 1.92$ & $9.81 \pm 2.37$ & 0.155 \\
\hline $6 M$ & $\begin{array}{c}59.12 \pm 14.12 \\
(N=153)\end{array}$ & $\begin{array}{c}65.84 \pm 15.17 \\
(N=45)\end{array}$ & $\begin{array}{c}64.72 \pm 16.19 \\
(N=24)\end{array}$ & 0.012 & $12.09 \pm 3.31$ & $12.66 \pm 2.7$ & $12.53 \pm 3.44$ & 0.529 \\
\hline $9 M$ & $\begin{array}{c}68.57 \pm 16 \\
(N=155)\end{array}$ & $\begin{array}{c}75.32 \pm 17.07 \\
(N=43)\end{array}$ & $\begin{array}{c}69.85 \pm 20 \\
(N=13)\end{array}$ & 0.063 & $14.03 \pm 3.65$ & $14.59 \pm 3.55$ & $13.41 \pm 4.72$ & 0.537 \\
\hline $12 \mathrm{M}$ & $\begin{array}{c}75.4 \pm 18.13 \\
(N=160)\end{array}$ & $\begin{array}{c}79.66 \pm 20.4 \\
(N=44)\end{array}$ & $\begin{array}{c}79.13 \pm 18.34 \\
(N=12)\end{array}$ & 0.359 & $15.45 \pm 3.98$ & $15.39 \pm 4.12$ & $15 \pm 3.94$ & 0.928 \\
\hline $18 M$ & $\begin{array}{c}77.92 \pm 18.44 \\
(N=155)\end{array}$ & $\begin{array}{c}84.54 \pm 20.09 \\
(N=23)\end{array}$ & - & 0.114 & $16.08 \pm 4.3$ & $15.95 \pm 3.55$ & - & 0.888 \\
\hline $24 M$ & $\begin{array}{c}77.6 \pm 19.87 \\
(N=155)\end{array}$ & $\begin{array}{c}88.61 \pm 15.75 \\
(N=11)\end{array}$ & - & 0.074 & $15.9 \pm 4.3$ & $16.64 \pm 4.44$ & - & 0.587 \\
\hline $36 M$ & $\begin{array}{c}73.11 \pm 21.07 \\
(N=149)\end{array}$ & $\begin{array}{c}87.45 \pm 9.88 \\
(N=7)\end{array}$ & - & 0.076 & $15.06 \pm 4.58$ & $17.49 \pm 2.31$ & - & 0.167 \\
\hline
\end{tabular}

${ }^{\dagger} B P L-50 \mathrm{~cm}$ and $A L-150 \mathrm{~cm},{ }^{\ddagger} B P L-150 \mathrm{~cm}$ and $A L-50 \mathrm{~cm},{ }^{\S} B P L-100 \mathrm{~cm}$ and $A L-100 \mathrm{~cm}, D-$ day, M - month, ANOVA was used for comparisons $\leq 12$ months and independent sample t-test was used for comparisons afterwards; none of the Ps were significant. 
Table III. The effect of three limb length groups on outcomes over 12 months follow-up

\begin{tabular}{|c|c|c|c|c|}
\hline \multirow[t]{2}{*}{ Variable } & \multicolumn{2}{|l|}{$\% E W L$} & \multicolumn{2}{|l|}{$\Delta \mathrm{BMI}$} \\
\hline & Mean differencell $(95 \% \mathrm{Cl})$ & $P$-value & Mean difference $(95 \% \mathrm{Cl})$ & $P$-value \\
\hline \multicolumn{5}{|l|}{ Limb length group: } \\
\hline Group $1^{\dagger}$ & $-1.05(-5.3,3.19)$ & 0.625 & $-0.37(-1.28,0.53)$ & 0.42 \\
\hline Group $2^{\ddagger}$ & $2.85(-2.01,7.71)$ & 0.25 & $0.2(-0.8,1.2)$ & 0.68 \\
\hline Group $3^{\S}$ & - & & - & \\
\hline Time & $5.13(4.92,5.34)$ & $<0.001$ & $1.04(0.99,1.08)$ & $<0.001$ \\
\hline Baseline BMI (< 50 vs. $\geq 50$ ) & $6.85(3.83,9.88)$ & $<0.001$ & $-2.65(-3.41,-1.88)$ & $<0.001$ \\
\hline
\end{tabular}

Table IV. The effect of two limb length groups with outcomes over 36 months follow-up

\begin{tabular}{|c|c|c|c|c|}
\hline \multirow[t]{2}{*}{ Factor } & \multicolumn{2}{|l|}{$\% E W L$} & \multicolumn{2}{|l|}{$\Delta \mathrm{BMI}$} \\
\hline & Mean difference ${ }^{\S}(95 \% \mathrm{Cl})$ & $P$-value & Mean difference $(95 \% \mathrm{Cl})$ & $P$-value \\
\hline \multicolumn{5}{|l|}{ Limb length group: } \\
\hline Group $1^{\dagger}$ & $-5.43(-8.95,-1.91)$ & 0.002 & $-0.88(-1.52,-0.24)$ & 0.007 \\
\hline Group $2^{\ddagger}$ & - & & - & \\
\hline Time & $1.6(1.5,1.7)$ & $<0.001$ & $0.32(0.3,0.34)$ & $<0.001$ \\
\hline Baseline BMI (< 50 vs. $\geq 50)$ & $8.25(4.59,11.93)$ & $<0.001$ & $-3.07(-3.97,-2.17)$ & $<0.001$ \\
\hline
\end{tabular}

${ }^{\dagger} B P L-50 \mathrm{~cm}$ and $A L-150 \mathrm{~cm},{ }^{\ddagger} B P L-150 \mathrm{~cm}$ and $A L-50 \mathrm{~cm},{ }^{\$} / \mathrm{I} f 95 \%$ confidence interval excludes the value of 0 it is statistically significant.

gastrojejunostomy three days after the surgery and one patient due to fulminant hemolysis which led to multi-organ failure (due to anaphylaxis reaction to cephalosporins). Four patients experienced a leak; $5(2 \%)$ patients had obstruction which resulted in readmission and were treated with surgery.

Two $(0.8 \%)$ patients died late due to non-surgery related reasons. Hypoalbuminemia was observed in $8(3.2 \%)$ cases. Gallstone and intolerance of the bariatric surgery were not reported. Patients' complaints of smelly stool, constipation, dry skin, and hair loss were significantly different between the limb length groups. Weight loss failure was observed in $11(4.4 \%)$ cases.

\section{Discussion}

Despite the invention of new bariatric surgical procedures, RYGB has been considered as a gold standard procedure which is malabsorptive and restrictive $[10,15]$. The impact of BPL and $A L$ lengths on RYGB outcomes is still controversial regarding appropriate limb lengths $[6,8,10,11,15-18]$, de- spite the established relationship between patients' height and total small bowel length [15].

In our study, there was no significant difference in weight loss outcomes between different limb length groups over 12 months after RYGB. However, \%EWL was significantly higher in the patients with longer BPL and shorter AL during 36 months postoperatively. Feng et al. found that long and short Roux limbs had no significant effect on \%EWL and \%BMI loss, one year after RYGB in morbidly obese patients with $\mathrm{BMI}<50 \mathrm{~kg} / \mathrm{m}^{2}[16]$. Inabnet et al. found that the mean \%EWL in 2 years follow-up did not have a significant association with longer BPL $(100 \mathrm{~cm}$ vs. $50 \mathrm{~cm}$ ) and only internal herniation was more common in the group with longer BPL [9]. A report by Kaska et al. revealed that there was no significant difference in BMI in RYGB patients with long BPL $(100-150 \mathrm{~cm})$ and short BPL $(50-75 \mathrm{~cm}) 2$ years after the surgery [8]. Another study also showed the non-significant effect of BPL and $A L$ on total weight loss 12 months after RYGB [11]. These studies had a compatible finding with our unadjusted and ad- 
Table V. N (\%) of early and late complications in three limb length groups up to 36 months

\begin{tabular}{|c|c|c|c|c|}
\hline Complications & $\begin{array}{l}\text { Group } 1^{\dagger} \\
(n=172)\end{array}$ & $\begin{array}{l}\text { Group } 2^{\ddagger} \\
(n=48)\end{array}$ & $\begin{array}{l}\text { Group } 3^{\S} \\
(n=32)\end{array}$ & $P$-value \\
\hline \multicolumn{5}{|l|}{ Early ( $\leq 30$ days): } \\
\hline Death & $2(0.8)$ & 0 & 0 & 1 \\
\hline Leak & $3(1.2)$ & $1(0.4)$ & 0 & 1 \\
\hline Bleeding & $5(2)$ & 0 & 0 & 0.63 \\
\hline ICU required (postoperative) & $11(0.44)$ & $3(1.2)$ & 0 & 0.39 \\
\hline Obstruction" & $5(2)$ & 0 & 0 & 0.63 \\
\hline Pouch dilatation & $2(0.8)$ & 0 & 0 & 1 \\
\hline Wound infection & $1(0.4)$ & 0 & 0 & 1 \\
\hline Intra-abdominal abscess & $1(0.4)$ & 0 & 0 & 1 \\
\hline \multicolumn{5}{|l|}{ Late (> 30 days): } \\
\hline Death & $2(0.8)$ & 0 & 0 & 1 \\
\hline Hypoalbuminemia" & $6(2.4)$ & $2(0.8)$ & 0 & 0.64 \\
\hline Dumping & $36(14.4)$ & $5(2)$ & $8(3.2)$ & 0.18 \\
\hline Smelly stool & $57(22.8)$ & $25(10)$ & $16(12.4)$ & 0.023 \\
\hline Stricture & $1(0.4)$ & 0 & 0 & 1 \\
\hline Stomal ulcer & $1(0.4)$ & 0 & 0 & 1 \\
\hline GERD & 0 & $1(0.4)$ & $1(0.4)$ & 0.1 \\
\hline Hernia & $1(0.4)$ & 0 & 0 & 1 \\
\hline Vomiting & $28(11.2)$ & $6(12.5)$ & $8(0.25)$ & 0.32 \\
\hline Constipation & $5(2)$ & $12(4.8)$ & $14(5.6)$ & $<0.001$ \\
\hline Diarrhea & $13(5.2)$ & $8(3.2)$ & $6(2.4)$ & 0.057 \\
\hline Dry skin & $5(2)$ & $16(12.4)$ & $16(12.4)$ & $<0.001$ \\
\hline Hair loss & $5(2)$ & 25 (10) & $21(8.4)$ & $<0.001$ \\
\hline
\end{tabular}

${ }^{\dagger} B P L-50 \mathrm{~cm}$ and $A L-150 \mathrm{~cm},{ }^{\ddagger} B P L-150 \mathrm{~cm}$ and $A L-50 \mathrm{~cm},{ }^{\S} B P L-100 \mathrm{~cm}$ and $A L-100 \mathrm{~cm}$, "Obstruction that resulted in readmission and treated by surgery, "Albumin $3.5 \mathrm{mg} / \mathrm{dl}$, GERD - gastroesophageal reflux disease.

justed (for time and baseline BMI) results, demonstrating no significant association between limb length and either \%EWL or BMI change.

On the other hand, similar to our findings in 36 months postoperatively, Nergaard et al. observed that long BPL $(200 \mathrm{~cm})$ had more significant weight loss in comparison to short BPL $(60 \mathrm{~cm}), 18$ months after RYGB, which was persistent in follow-ups for 7 years [6]. It is also reported that \%EWL at 18 months was greater in patients with a shorter $\mathrm{AL}$ $(100 \mathrm{~cm})$ in $\mathrm{BMI}<50 \mathrm{~kg} / \mathrm{m}^{2}$ compared with a longer $\mathrm{AL}(150 \mathrm{~cm})$ in patients with $\mathrm{BMI}>50 \mathrm{~kg} / \mathrm{m}^{2}$; how- ever, \%EWL did not differ after 24 months follow-up [10], which may be related to the BMI difference in morbidly obese and super-obese patients. In our study, the direction of association between limb length and \%EWL as well as BMI change was similar to both studies. The findings of the present study showed that the association between \%EWL and limb length was not significant over a short-term follow-up, whereas it was significant over a midterm follow-up. Moreover, we have incorporated the effect of time as well as patient's BMI at the baseline in the analysis. 
Another study by Gleysteen et al. compared three different lengths of AL limb groups (41-61 cm, 130-160 cm, 115-250 cm about one third of total bowel length) with five years follow-up. They found that longer AL has better weight loss outcomes only in super-obese $\left(B M I>50 \mathrm{~kg} / \mathrm{m}^{2}\right)$ patients, not in morbidly obese patients, and also concluded that there is no need to measure whole small bowel length [7]. Moreover, Ciovica et al. found that longer AL $(150 \mathrm{~cm})$ had a greater effect on weight loss and $\% E W L$ in the $1^{\text {st }}$ year after RYGB compared to shorter AL $(100 \mathrm{~cm})$ [18]. The findings of these studies are completely different from our study. In most of these studies, small bowel length was not measured like in our study. So, this controversy between different studies should be interpreted with caution because of the essential role of common channel limb length on weight regain, which has been ignored.

Similar studies concluded that the length of AL and BPL has no significant impact on complications and nutritional deficiencies after RYGB $[9,16,17]$. The reason for these different results may be the wide variety in choice of limb length, the number of patients, the method of data analysis, and follow-up duration. The lack of difference between the three groups in \%EWL (at 12 months) was likely due to type II error which occurred because of the small sample size in group 2. Limited follow-up in the group 3 patients, limb length variety within the groups (which could have resulted in residual confounder), small sample size at 36 months follow-up, and lack of measurement of the entire small bowel length, which is quite variable among people, are limitations of this study.

\section{Conclusions}

There was no significant relationship between the length of BPL and AL and weight loss outcomes over short-term follow-up (12 months); however, the patients with longer BPL and shorter AL length had a greater weight loss regarding \%EWL and BMI change over mid-term follow-up (36 months) after RYGB.

\section{Acknowledgments}

The authors would like to thank the Rasoul Akram Clinical Research Development Center (RCRDC) for its technical and editorial assistance.

This study is granted by Iran University of Medical Sciences (Grant code: 95-02-140-27472).

\section{Conflict of interest}

The authors declare no conflict of interest.

\section{References}

1. Hernández-Martínez J, Calvo-Ros MÁ. Gastric by-pass with fixed 230-cm-long common limb and variable alimentary and biliopancreatic limbs in morbid obesity. Obes Surg 2011; 21: 1879-86.

2. Thurnheer M, Bisang P, Ernst B, et al. A novel distal very long Roux-en $Y$ gastric bypass (DVLRYGB) as a primary bariatric procedure - complication rates, weight loss, and nutritional/ metabolic changes in the first 355 patients. Obes Surg 2012; 22: $1427-36$

3. Welbourn R, Pournaras DJ, Dixon J, et al. Bariatric surgery worldwide: baseline demographic description and one-year outcomes from the Second IFSO Global Registry Report 20132015. Obes Surg 2017: 1-10.

4. Schijns W, Ligthart MA, Berends FJ, et al. Changes in iron absorption after roux-en-Y gastric bypass. Obes Surg 2018; 28: 1738-44.

5. Angrisani L, Santonicola A, lovino P, et al. IFSO Worldwide Survey 2016: primary, endoluminal, and revisional procedures. Obes Surg 2018; 28: 3783-94.

6. Nergaard BJ, Leifsson BG, Hedenbro J, et al. Gastric bypass with long alimentary limb or long pancreato-biliary limb - long-term results on weight loss, resolution of co-morbidities and metabolic parameters. Obes Surg 2014; 24: 1595-602.

7. Gleysteen JJ. Five-year outcome with gastric bypass: Roux limb length makes a difference. Surg Obes Relat Dis 2009; 5: 242-7.

8. Kaska t, Kobiela J, Proczko M, et al. Does the length of the biliary limb influence medium-term laboratory remission of type 2 diabetes mellitus after Roux-en-Y gastric bypass in morbidly obese patients? Videosurgery Miniinv 2014; 9: 31-9.

9. Inabnet WB, Quinn T, Gagner M, et al. Laparoscopic Roux-en-Y gastric bypass in patients with $\mathrm{BMI}<50$ : a prospective randomized trial comparing short and long limb lengths. Obes Surg 2005; 15: 51-7.

10. Dogan K, Homan J, Aarts EO, et al. A short or a long Roux limb in gastric bypass surgery: does it matter? Surg Endosc 2017; 31: 1882-90.

11. Valezi AC, Marson AC, Merguizo RA, et al. Roux-en-Y gastric bypass: limb length and weight loss. Arq Bras Cir Dig 2014; 27 : 56-8.

12. Brethauer S, Kim J, el Chaar M, et al. Standardized outcomes reporting in metabolic and bariatric surgery. Surg Obes Relat Dis 2015; 11: 587-606

13. Mann JP, Jakes AD, Hayden JD, et al. Systematic review of definitions of failure in revisional bariatric surgery. Obes Surg 2015; 25: $571-4$

14. Fitzmaurice G, Molenberghs G, Davidian M, et al. Advances in Longitudinal Data Analysis. Chapman and Hall/CRC 2008; 13-38.

15. Navez B, Thomopoulos T, Stefanescu I, et al. Common limb length does not influence weight loss after standard laparoscopic Roux-en-Y gastric bypass. Obes Surg 2016; 26: 1705-9. 
16. Feng JJ, Gagner M, Pomp A, et al. Effect of standard vs extended Roux limb length on weight loss outcomes after laparoscopic Roux-en-Y gastric bypass. Surg Endosc 2003; 17: 1055-60.

17. Lee S, Sahagian KG, Schriver JP. Relationship between varying Roux limb lengths and weight loss in gastric bypass. Curr Surg 2006; 63: 259-63.

18. Ciovica R, Takata M, Vittinghoff E, et al. The impact of roux limb length on weight loss after gastric bypass. Obes Surg 2008; 18: $5-10$.

Received: 25.08.2019, accepted: 3.10.2019. 